\title{
A Complicated Tonsillitis: Lemierre's Syndrome
}

\section{Moreno Díaz Javier*, García Bruñén Jose Miguel, Loscos Aranda Silvia and Arenas Miquelez Aránzazu Inmaculada}

Internal Medicine Service, University Hospital Miguel Servet, Spain

*Corresponding author: Javier Moreno Díaz, Internal Medicine Service, University Hospital Miguel Servet, Isabel la Catolica Avenue, num. 1-3. Postal Code 50006, Zaragoza, Spain, Tel: +34-687216658

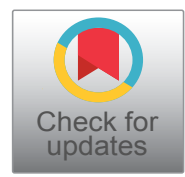

\begin{abstract}
Lemierre's syndrome is a rare complication of tonsillitis, with septic emboli and jugular vein thrombosis. We present a case in a young adult without immune deficiencies that required purulent collection drainage and admission to the Intensive Care Unit. This entity, although rare, is potentially fatal and should be known for early diagnosis and treatment.
\end{abstract}

\section{Keywords}

Tonsillitis, Septic embolism, Jugular thrombosis, Lemierre's syndrome

\section{Introduction}

Lemierre's syndrome is a very rare septic complication of acute tonsillitis [1]. In general, the causative agent in most cases is Fusobacterium necrophorum, an anaerobic gram-negative microorganism common in oral flora $[2,3]$. We present a case of an adult with a history of acute tonsillitis and the subsequent fever, jugular thrombosis and septic emboli.

\section{Case Report}

A 22-years-old male, born in Romania, with no allergies or medical antecedents was admitted in the emergency room. He was diagnosis of viral tonsillitis treated with NSAIDs.

After 72 hours he presents breakdown with fever up to $39^{\circ} \mathrm{C}$ and the appearance of a right cervical tumour.

The blood test showed an increase in leukocytes with neutrophilia and Reactive C Protein of $19 \mathrm{mgr} / \mathrm{dL}$ (normal range 0-0.5 $\mathrm{mg} / \mathrm{dl}$ ).

A cervical ultrasound was performed, which showed right internal jugular thrombosis with an abscess of 25 $\times 7 \mathrm{~mm}$ depending on the right tonsil.

The otolaryngologist decided to admit the patient and he started treatment with high dose amoxicillin/ clavulanic acid, dexamethasone. A laryngoscopy is performed, showing a protrusion on the right side of the cavum.

The patient presents a torpid evolution with low blood pressure despite the antibiotic treatment administered and because of this an Internal Medicine Specialist was consulted.

Lemierre's Syndrome is suspected at that moment, so

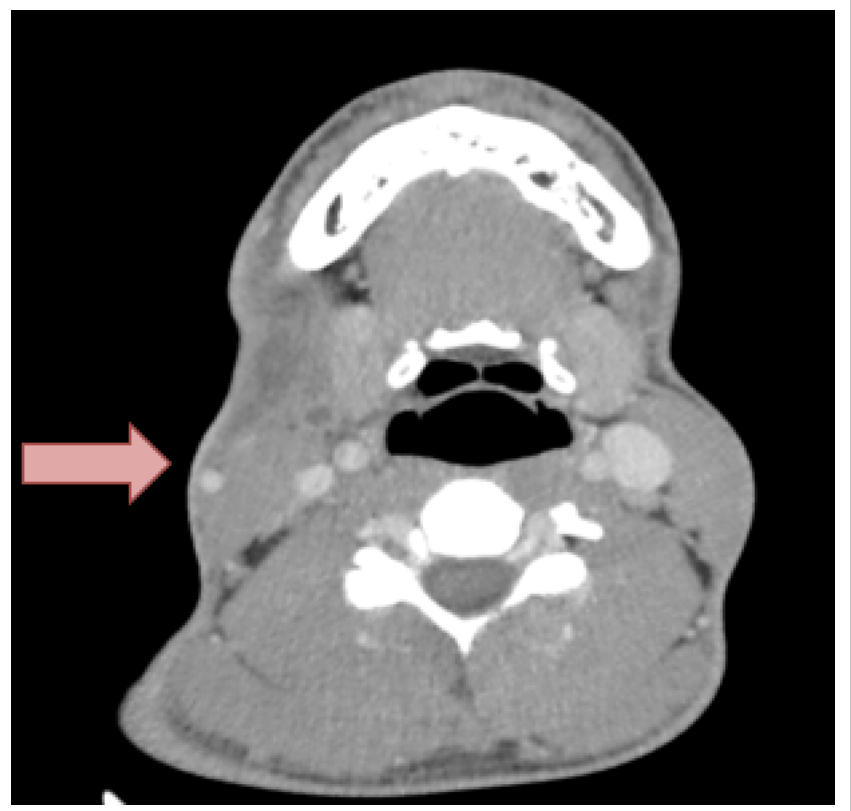

Figure 1: Soft tissue edema and jugular vein thrombosis.

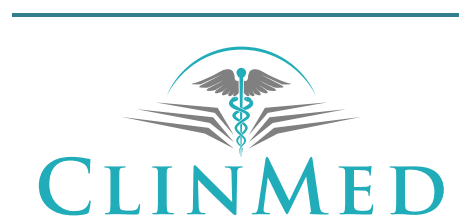

INTERNATIONAL LIBRARY

Citation: Moreno Díaz J, Miguel GBJ, Silvia LA, Inmaculada AMA (2018) A Complicated Tonsillitis: Lemierre's Syndrome. Int Arch Intern Med 2:004.

Accepted: September 05, 2018: Published: September 07, 2018

Copyright: (c) 2018 Moreno Díaz J, et al. This is an open-access article distributed under the terms of the Creative Commons Attribution License, which permits unrestricted use, distribution, and reproduction in any medium, provided the original author and source are credited. 
that a Cervico-Thoraco-Abdominal CT scan is indicated. This proof confirmed the tonsillar abscess and thrombosis of the right jugular vein (Figure 1). In addition, a pulmonary abscess and pleural effusion is reported and septic embolisms in the spleen (Figure 2 and Figure 3 ).

The antibiotic regimen was modified to a combination of Vancomycin with Meropenem, indicating by the Otorhinolaryngology service the carrying out of urgent surgery to drain the tonsillar abscess.

After surgery, the patient is admitted to the Intensive Care Unit due to dyspnea, tachypnea and low blood pressure, requiring thoracic drainage from the pulmonary collection.

After confirming the stabilization of the patient, it goes to the hospitalization plant where it was maintained empirical antibiotic therapy for 14 days, sequenced to levofloxacin with metronidazole with good response.

No bacterial growth was obtained in blood cultures or in purulent material as serologist for HIV, syphilis, $\mathrm{HCV}$ and $\mathrm{HBV}$ were negative.

Finally, he is discharged to complete two more weeks of oral antibiotic therapy and 6 months of oral anticoagulation with acenucumarol.

\section{Discussion}

Lemierre's syndrome or "postangine sepsis" is a rare

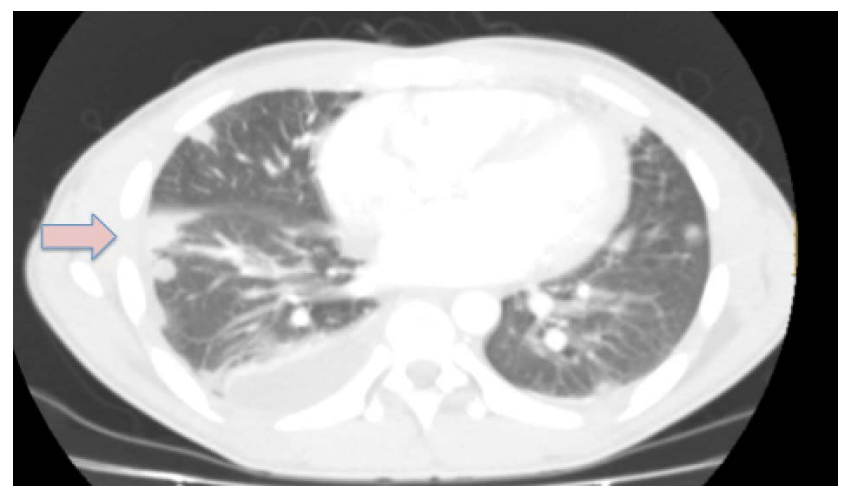

Figure 2: Pulmonary abscess and associated pleural effusion.

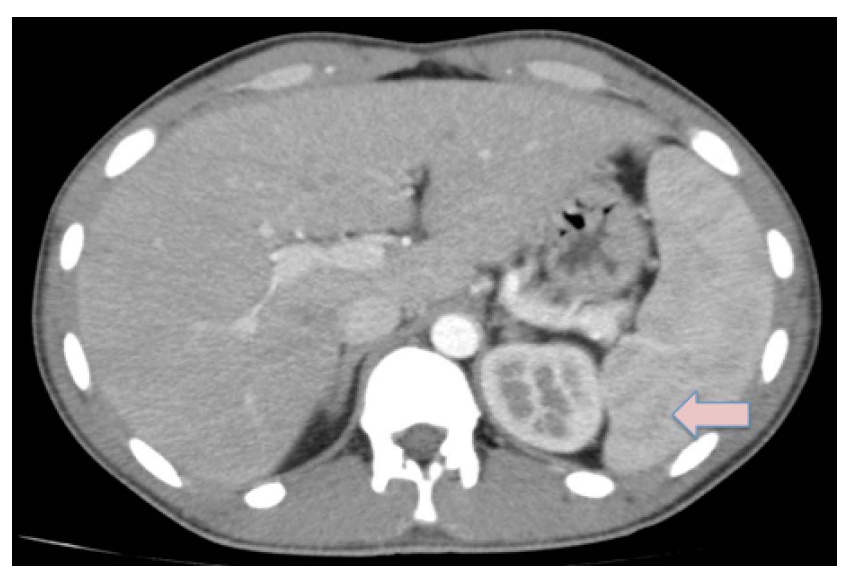

Figure 3: Splenic abscesses. complication of oropharyngeal infections that usually affects healthy young people $[3,4]$.

The causative agent in most cases is Fusobacterium necrophorum [5], a gram-negative anaerobic microorganism, although other germs capable of causing this disease to have been described [6]. In our case, no microbiological growth was observed.

This syndrome, which occurs between 4 and 12 days after pharyngotonsillitis, is characterized by thrombosis of the internal jugular vein associated with septic pulmonary embolisms that can progress to severe sepsis [7], as described in our case. The clinical picture is typically preceded by pharyngitis, tonsillitis or peritonsillar abscess with high fever, which is followed by a thrombosis of the internal jugular vein. The patient usually presents pain around the angle of the jaw or parallel to the sternocleidomastoid muscle. The presentation of our patient with pharyngitis and cervical pain has been previously described in the literature with a frequency of $76 \%[8,9]$.

The septic emboli from the jugular vein facilitate the metastatic spread of the disease and the formation of abscesses in the lung, liver and joints. Pulmonary abscesses can lead to acute respiratory failure, which sometimes requires ventilatory support [3]. Septic emboli are a frequent complication [9], with the lung being the most affected organ in $80 \%-90 \%$ of the time [7].

Chest radiology usually shows multiple ill-defined opacities, which sometimes cavitate and reflect the arrival of septic emboli. Although pleural effusion is common, empyema is uncommon. Pulmonary CT with contrast shows early cavitations as well as its relationship with distal pulmonary vessels. Cervical CT is also very sensitive to demonstrate thrombosis of the VYI, periamigdalar, parapharyngeal and intrathoracic veins; Although with lower diagnostic performance, ultrasound is a good alternative due to its accessibility and low cost. Nuclear magnetic resonance can be used in cases of allergy to iodinated contrasts and when ultrasound has not been useful to detect thrombosis, with the added advantage of not irradiating the patient [10].

Meningitis remains the most feared complication. There are local complications such as rupture of the carotid, Horner's syndrome, trapezius muscle paralysis and dysphagia, explained because in the posterior compartment of the parapharyngeal space accompanying the internal jugular vein, the carotid artery, the cranial nerves $I X, X, X I$ and $X I I$ and the cervical sympathetic trunk [7].

Today, the pillars of management are antibiotic therapy and surgical debridement of metastatic foci that require it (purulent arthritis, empyema, etc.) [7].

The optimal antibiotic treatment is not clear since, although $F$. necrophorum is usually sensitive to penicillin, clindamycin or metronidazole, failures have been re- 
ported in penicillin treatment probably due to the production of beta-lactamases. Recent recommendations include the combination of a beta-lactamase-resistant agent and metronidazole or clindamycin or monotherapy with imipenem. Treatment should be maintained at least 4 weeks at high doses [3].

The role of anticoagulation is controversial since there have been no controlled studies to confirm its efficacy [3]. Some authors argue that with such therapy there is a risk, at least theoretical, of facilitating the spread of the infection. On the other hand, there are those who defend its use based on the good results obtained in patients with septic pelvic thrombophlebitis. At the moment there is a consensus in the literature to initiate anticoagulation if fever persists or new septic emboli appear after 72 hours of antibiotic treatment, or if an entity that requires it occurs concomitantly, such as cerebral venous sinus thrombosis [9]. Jugular vein ligation can be considered in patients with uncontrolled sepsis or severe respiratory failure caused by repeated pulmonary emboli [3].

In conclusion, it seems important to continue considering this complication among the differential diagnoses of a case of tonsillitis or pharyngitis of torpid or septic evolution. It is a serious pathology that due to its low incidence may take time to be diagnosed, so a high index of suspicion is required before any septic symptoms in young people after an oropharyngeal infection. In these patients it is essential to use complementary images, management in centres of high complexity and interdisciplinary work [7].

\section{References}

1. Riordan T (2007) Human infection with fusobacterium necrophorum (Necrobacillosis), with a focus on Lemierre's syndrome. Clin Microbiol Rev 20: 622-659.

2. Noy D, Rachmiel A, Levy-Faber D, Emodi O (2015) Lemierre's syndrome from odontogenic infection: Review of the literature and case description. Ann Maxillofac Surg 5: 219-225.

3. Crespoa RM, Oteroa SQ, Gonzáleza AH, de Benito Guerraa MT, Trujillob IG, et al. (2005) Síndrome de Lemierre. La enfermedad olvidada Lemierre syndrome. The forgotten disease. Med Intensiva 29: 437-440.

4. Screaton NJ, Ravenel JG, Lehner PJ, Heitzman ER, Flower CD (1999) Lemierre syndrome: Forgotten but not extinct-report of four cases. Radiology 213: 369-374.

5. Ramirez S, Hild TG, Rudolph CN, Sty JR, Kehl SC, et al. (2003) Increased diagnosis of Lemierre syndrome and other fusobacterium necrophorum infections at a Children's Hospital. Pediatrics 112: e380.

6. Kristiasen LH, Prag J (2000) Human necrobacillosis with emphasis on Lemierre's syndrome. Clin Infect Dis 31: 524-532.

7. Matías Winter D, Andrea Saavedra B, Carolina Grau L, Jorge Caro $L$ (2013) Síndrome de lemierre, reporte de un caso lemierre syndrome: A case report. Rev Otorrinolaringol Cir Cabeza Cuello 73: 164-168.

8. Hagelskjaer L, Prag J, Malczynski J, Kristensen J (1998) Incidence and clinical epidemiology of necrobacillosis, including Lemierre's syndrome in Denmark 1990-1995. Eur J Clin Microbiol Infect Dis 17: 561-565.

9. Fernandez J, Dones I, Carcelen M, Gutierrez J, Lea C, et al. (2002) Syndrome de Lemierre. Descripción de dos nuevos casos y revisión de la literatura. An Med Interna 19: 139-142.

10. De Lima JE Jr, Levin M (2003) Lemierre's syndrome: Post-anginal septicemia. Pediatr Radiol 33: 281-283. 